Cott Pinegar received a B.A. in physics from the University of Colorado at $\checkmark$ Boulder in 2001 and has been an astrophysics and earth science Teacher at Pomona High School since 2001. He is a second year Laboratory Science Teacher Professional Development (LSTPD) teacher at the National Renewable Energy Laboratory (NREL). He is in the beginning stages of a masters program in Applied Mathematics at the University of Colorado at Denver.

$\mathrm{D}$ rek Nalley is a student at Purdue University who plans on becoming physics teacher. During the summer of 2005, he worked on research at National Renewable Energy Laboratory as part of the Pre-Service Teacher Program.
$\mathrm{K}$ eith Emery is currently a Group Manager in Cell and Module Performance and acting Group Manager of the Electro-Optical Characterization Groups at the National Renewable Energy Laboratory, responsible for photovoltaic cell and module calibrations and efficiency verification. He leads a team that is ISDO 17025 accredited for primary reference cell, secondary reference cell, and secondary module calibrations. Over the past 26 years, his group has supplied the PV community with a formal calibration traceability path and developed internationally accepted PV performance measurement procedure. Mr. Emery graduated from Michigan State University with a B.S. degree in Physics and a Masters in Electrical modeling chemical lasers. He also worked at Colorado State University on transparent conducting oxides on Si and chemical vapor deposited oxides and nitrides using lasers and electron beams.

\title{
LINEARITY TESTING OF PHOTOVOLTAIC CELLS
}

\author{
Scott Pinegar, Derek Nalley, and Keith Emery
}

\begin{abstract}
Photovoltaic devices are rated in terms of their power output or efficiency with respect to a specific spectrum, total irradiance, and temperature. In order to rate photovoltaic devices, a reference detector whose response is linear with total irradiance is needed. This procedure documents a procedure to determine if a detector is linear over the irradiance range of interest. Testing the short circuit current versus the total irradiance is done by illuminating a reference cell candidate with two lamps that are fitted with programmable filter wheels. The purpose is to reject nonlinear samples as determined by national and international standards from being used as primary reference cells. A calibrated linear reference cell tested by the two lamp method yields a linear result.
\end{abstract}

\section{INTRODUCTION}

Photovoltaic devices are rated by their power output over a specific total irradiance, spectrum, and temperature. Rating these systems requires a reference detector that must have a linear response over the ranges of interest according to the ASTM and IEC standards [8]. Measurements of linearity are usually done in two ways; measuring the short circuit current versus total irradiance as the total irradiance is varied, or measuring the quantum efficiency versus bias light $[1,2,3,4,5,6,7]$.

\section{Short Circuit Current vs. Total Irradiance}

The short circuit current $\left(\mathrm{I}_{\mathrm{sc}}\right)$ is measured over a shunt resistor connected to a sample that is illuminated over a varied total irradiance $\left(\mathrm{E}_{\text {tot }}\right)[1,2,3,4]$. Measuring $\mathrm{I}_{\mathrm{sc}}$ versus $\mathrm{E}_{\text {tot }}$ assumes that the spatial non-uniformity does not change as the total irradiance is varied. This method also assumes that the spectrum does not change with total irradiance because if the spectrum changes with total irradiance then the spectral error changes with total irradiance causing an error in the measured total irradiance. The last assumption is the temperature and ambient light stays constant throughout the test $[1,2,3,4]$.

\section{Quantum Efficiency vs. Bias Light}

Quantum efficiency or spectral irradiance $\mathrm{E}_{s}(\lambda)$ is measured versus the bias light $[5,6,7]$. The quantum efficiency versus bias light test requires a low noise quantum efficiency system that operates at low light levels and at the one sun value of $1000 \mathrm{~W} / \mathrm{m}^{2}$. The National Institute of Standards and Technology (NIST) in Boulder Colorado cannot perform this measurement in the range of irradiances useful to photovoltaics (PV) [9]. This method requires that the temperature of the sample stays constant which is critical because the quantum efficiency changes rapidly with cell temperature near the band gap. Finally the quantum efficiency method requires that 
the noise in the quantum efficiency measurement be independent of the bias light $[5,6,7]$.

\section{The Two Lamp Method}

The two lamp method circumvents some of these assumptions as well as factor them out completely. This method does not require a linear detector, takes a shorter time period to perform and does not require attended operation. In the absence of ambient lab light the following is true:

$$
\mathrm{I}_{\mathrm{sc}, \mathrm{AB}}=\mathrm{I}_{\mathrm{sc}, \mathrm{A}}+\mathrm{I}_{\mathrm{sc}, \mathrm{B}}
$$

where $I_{s c, A B}$ is the short circuit current produced when lamp A and lamp B are both incident on the reference cell. $\mathrm{I}_{\mathrm{sc}, \mathrm{A}}$ and $\mathrm{I}_{\mathrm{sc}, \mathrm{B}}$ are the short circuit currents produced when only lamp A or lamp B is incident on the reference cell. In order to factor out the ambient light ohms law says the following:

$$
\mathrm{V}_{\mathrm{lab}}=\left(\mathrm{I}_{\mathrm{sc}, \mathrm{lab}}\right) \mathrm{R}
$$

where $\mathrm{V}_{\text {lab }}$ is the voltage produced and $\mathrm{I}_{\mathrm{sc}, \text { lab }}$ is the short circuit current across a $0.10 \mathrm{ohm}$ shunt resistor $(\mathrm{R})$ produced by the ambient light in the lab. When a single lamp, lamp A, is incident on the sample the resulting voltage follows:

$$
\mathrm{V}_{\mathrm{A}}=\left(\mathrm{I}_{\mathrm{sc}, \mathrm{A}}+\mathrm{I}_{\mathrm{sc}, \mathrm{lab}}\right) \mathrm{R}
$$

where $\mathrm{V}_{\mathrm{A}}$ is the voltage produced and $\mathrm{I}_{\mathrm{sc}, \mathrm{A}}$ is the short circuit current produced by the light on the reference cell from lamp A alone. A similar situation follows for lamp B:

$$
\mathrm{V}_{\mathrm{B}}=\left(\mathrm{I}_{\mathrm{sc}, \mathrm{B}}+\mathrm{I}_{\mathrm{sc}, \mathrm{lab}}\right) \mathrm{R}
$$

again where $V_{B}$ is the voltage produced and $I_{s c, B}$ is the short circuit current produced by the light on the sample from lamp $B$ alone. Measuring the voltage from the reference cell when both lamp A and $\mathrm{B}$ are incident yields:

$$
\mathrm{V}_{\mathrm{AB}}=\left(\mathrm{I}_{\mathrm{sc}, \mathrm{AB}}+\mathrm{I}_{\mathrm{sc}, \mathrm{lab}}\right) \mathrm{R}
$$

where

$$
\mathrm{V}_{\mathrm{AB}}=\mathrm{V}_{\mathrm{A}}+\mathrm{V}_{\mathrm{B}}
$$

and

$$
\mathrm{I}_{\mathrm{sc}, \mathrm{AB}}=\mathrm{I}_{\mathrm{sc}, \mathrm{A}}+\mathrm{I}_{\mathrm{sc}, \mathrm{B}}
$$

substituting equations (1) - (4) into equation (6) yields:

$$
\mathrm{V}_{\mathrm{AB}} / \mathrm{R}=\mathrm{V}_{\mathrm{A}} / \mathrm{R}+\mathrm{V}_{\mathrm{B}} / \mathrm{R}-\mathrm{V}_{\mathrm{lab}} / \mathrm{R}
$$

A plot of $V_{A B}$ versus $\left(V_{A}+V_{B}-V_{\text {lab }}\right)$ should give a straight line which according to the ASTM and IEC standards must have a percent standard deviation of the slope of $0.02 \%$. The percent standard deviation $(s)$ in percent is:

$$
s=\text { standard deviation/slope } \mathrm{x} 100 .
$$

Some advantages to this method are that the test is insensitive to spatial non-uniformity, insensitive to spectral variation and does not require a linear detector. Also the ambient light from the lab can be factored out completely. According to ASTM standards E1143 and E1125 a primary reference cell is required to be linear. The primary goal of this test is to reject nonlinear samples from being used as primary reference cells.

\section{MATERIALS AND METHODS}

Four assumptions made with the two lamp method test are that the lamp outputs, the filter transmittance, the ambient lab light, and test cell temperature all stay constant throughout the test. The equations we use allow us to factor out the ambient lab light $\left(\mathrm{V}_{\mathrm{lab}}\right)$ completely which eliminates one source of error. The test bed for the experiment consists of two Spectra-Physics lamps model number 66860 and 66861 powered by IEEE-488 programmable low noise Sorensen DCS60-18E power supplies $[13,14]$. The 400 watt lamps operate at a maximum 19 volts and 8 amps (see Figure 1). The spectral irradiance of the lamps illuminating a single area both at 8 amps is shown in Figure 2. The spectral irradiance shown in Figure 2

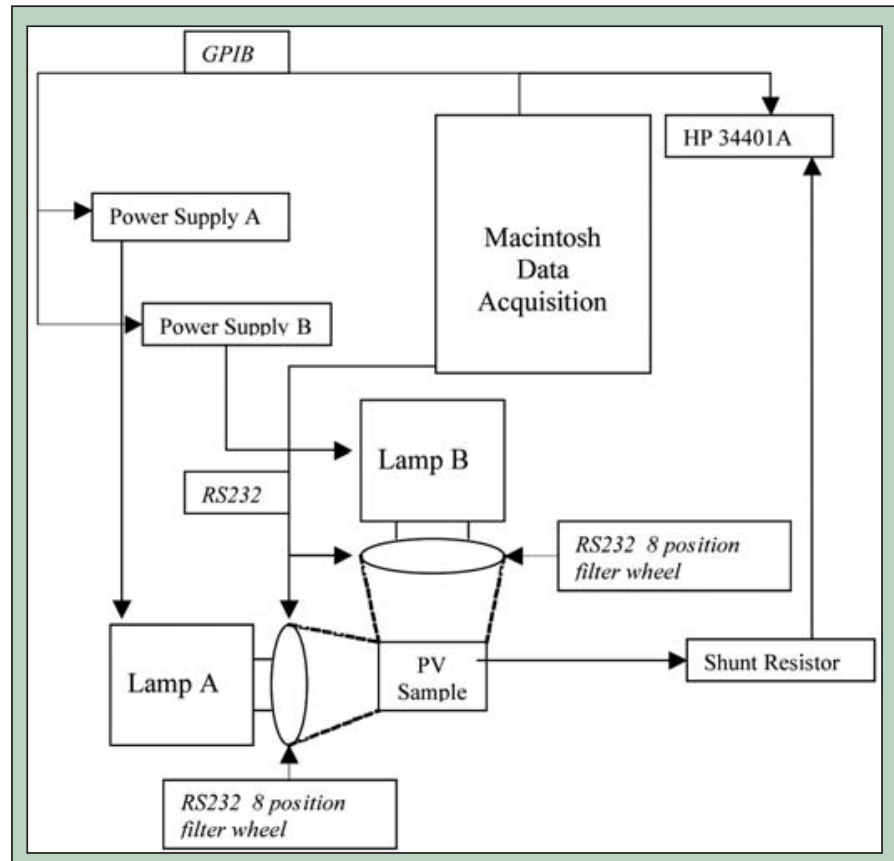

Figure 1. Block diagram of Linearity Test Bed.

is approximately 2 suns or $2000 \mathrm{~W} / \mathrm{m}^{2} / \mathrm{nm}$. The spectral irradiance is taken over a wavelength range of approximately $300 \mathrm{~nm}$ to $1200 \mathrm{~nm}$. The lamps intensity is controlled with metallic neutral density filters mounted in eight position RS232 programmable filter wheels [12]. The transmission curve for each filter as a function of wavelength can 


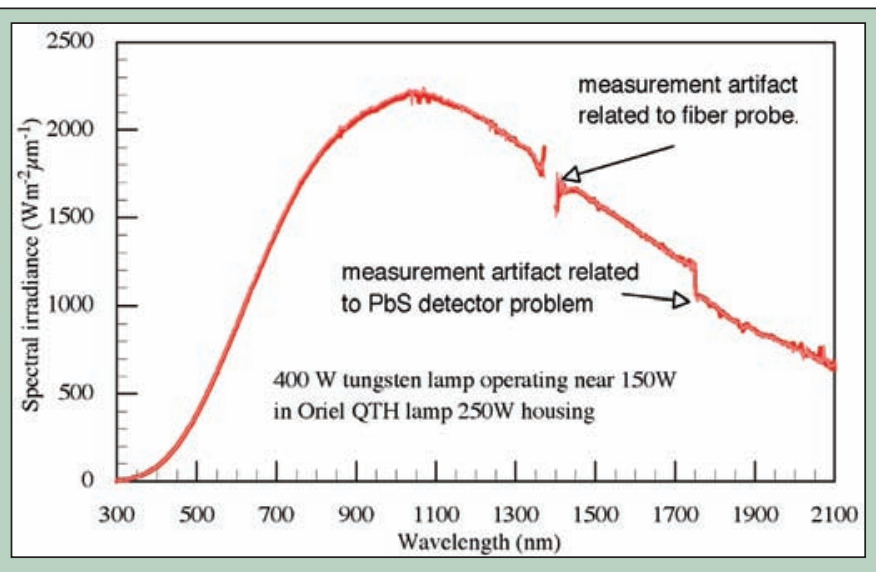

Figure 2. Unattenuated Spectral Irradiance versus Wavelength of Lamp A measured twice.

be seen in Figure 9 as well as a table of the percent transmission for each filter in Table 1 . The transmission ranges from $100 \%$ where no filter is added to opaque which has $0 \%$ transmittance. To minimize

\begin{tabular}{|c|c|c|c|c|}
\hline Wheel & $\begin{array}{c}\text { Filter } \\
\text { Transmittance }\end{array}$ & & Wheel & $\begin{array}{c}\text { Filter } \\
\text { Transmittance }\end{array}$ \\
\cline { 1 - 2 } A1 & Opaque & B1 & Opaque \\
\hline A2 & Blank & $79 \%$ & B2 & Blank \\
\hline A3 & $63 \%$ & B3 & $79 \%$ \\
\hline A4 & $50 \%$ & B4 & $63 \%$ \\
\hline A5 & $40 \%$ & B5 & $50 \%$ \\
\hline A6 & $33 \%$ & B6 & $40 \%$ \\
\hline A7 & $25 \%$ & B7 & $33 \%$ \\
\hline A8 & B8 & $25 \%$ \\
\hline
\end{tabular}

Table 1. Filter Transmittance for lamp A and B.

uncertainties, the maximum and minimum level of the lights should be within a factor of 5. Different ranges of total irradiances are achieved by varying the lamp voltage. The sample is placed in the test plane where it will be illuminated by light from each lamp after the light has passed through the filter wheels. This allows the sample to be illuminated by the two light sources as if it were from one light source. The ability to apply different voltages to the lamps allows a wide range of light levels to be tested which results in a wide range of $\mathrm{E}_{\text {tot }}$ on the sample. This gives us an $\mathrm{I}_{\mathrm{sc}}$ across the current sense resistor which is chosen in such a way to allow only $20 \mathrm{mV}$ across the sample as specified in the standards [8]. The $\mathrm{I}_{\mathrm{sc}}$ versus $\mathrm{E}_{\text {tot }}$ curve will determine the linearity or nonlinearity of the sample. The voltages and filter rotations are chosen by us which allows a view of certain regions of the sample response. The Labview program that runs our test bed collects the data and displays a graphical representation on the screen while saving the data to a designated file.

\section{RESULTS}

The 930216-1 primary reference cell calibrated by PhysikalischTechnische Bundersanstalt (PTB) in Braunschweig Germany and determined to be linear is used to test the validity of the two lamp method [10,11]. Figure 3 shows linear calibration data from PTB done two different times. Once PTB calibrated the 930216-1 reference cell to be linear in 1998 as published in PEP'93 [10] and again in 2004 given in the calibration certificate [11]. Figure 3 also shows the National Renewable Energy Lab (NREL) results from the two lamp method. The data has been normalized such that a

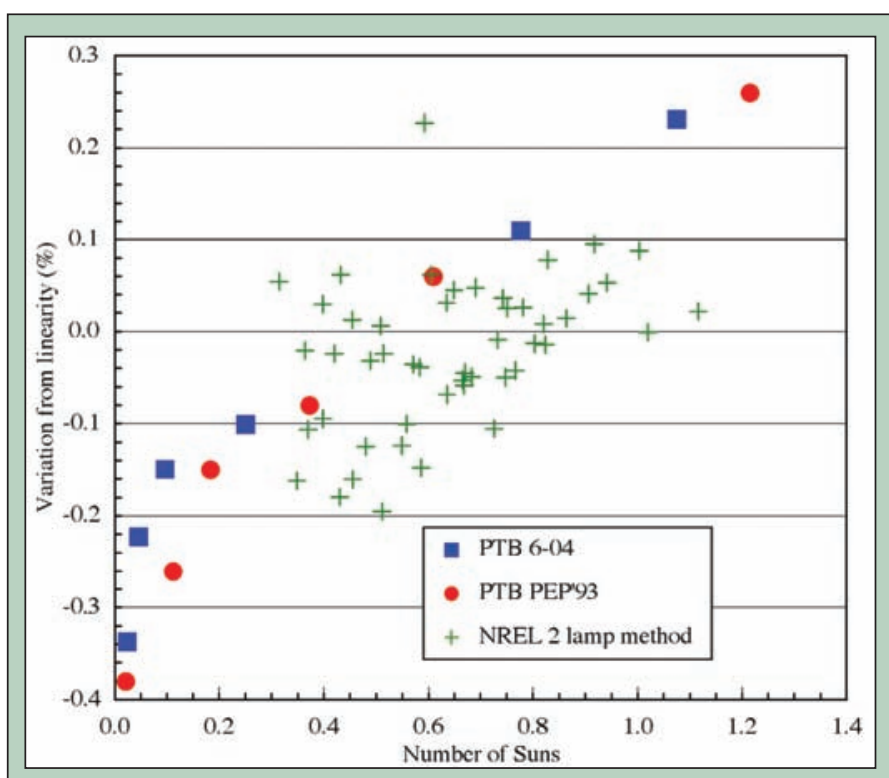

Figure 3. Reference Cell 930216 PTB and NREL Normalized Data

horizontal line shows linearity. This method of determining linearity differs from the standards which state the standard deviation from the slope where this method looks at the variation from linearity which may be a more accurate method of looking at linearity. The PTB data varies from linear by almost $0.7 \%$ ranging from $-0.4 \%$ to $0.3 \%$. The NREL data also falls within this range of variation. Over the irradiance of interest $(0.6-1.1$ suns) the range for both PTB and NREL is a much better range, approximately -0.15 to $0.1 \%$. This is a difference of approximately $0.25 \%$ variation from linearity. The PTB and NREL data both result in a s of less than $2 \%$ classifying the reference cell to be linear as specified in the standards [8]. This gives evidence of the validity of the two lamp method as a legitimate test for linearity.

Doing a numerical study using functions that are known to be nonlinear overall helps in further determining the validity of the two lamp method. For convenience and clarity, $\mathrm{E}_{\mathrm{tot}}$ on the $\mathrm{x}$-axis for Figures 5-8 has been transformed to the number of suns. The exponential function in the form of $y=A e^{B x}$ gives the results as seen in Figure 4, where A is 100, B is 0.00015 , $\mathrm{x}$ represents Etot and $y$ represents $I_{s c}$. With these values given in the equation and specifying the range of $0-1$ suns for $\mathrm{E}_{\text {tot }}$ as value of $0.02 \%$ results. Using the two lamp method with the same $\mathrm{E}_{\text {tor }}$ range gives a $s$ value of $0.00001 \%$, much less than the actual $s$ value (see Figures 5-6). This fact is due to the chosen function and the range over which the A + B method is collected. Over a small enough range the A + B method will give a linear result of any curve but widening the range between $\mathrm{A}$ and $\mathrm{B}$ when added together the $s$ value will be greater. 


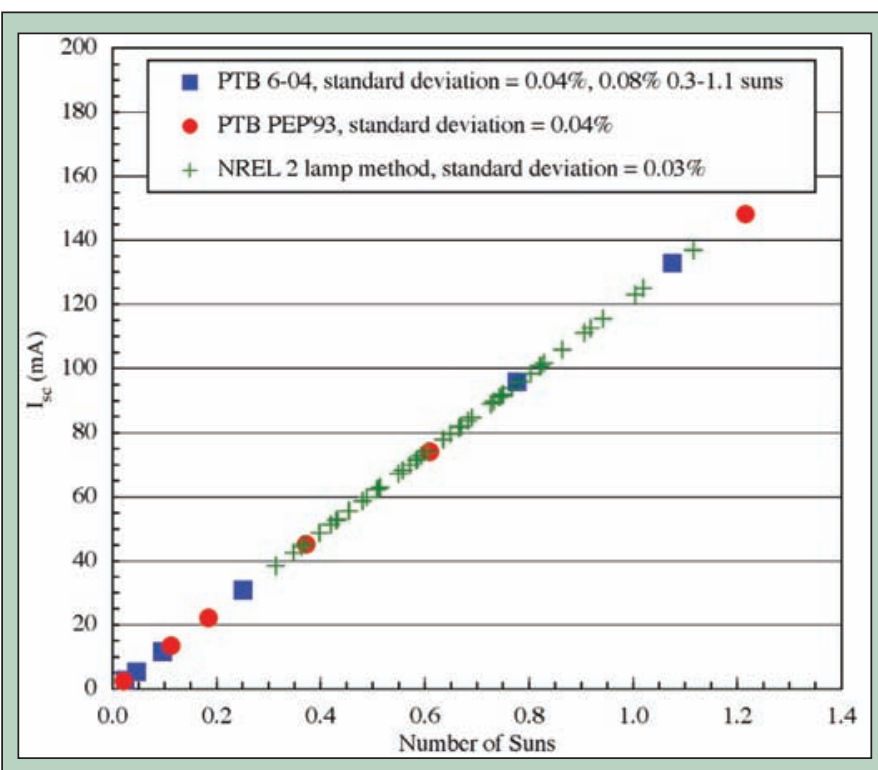

Figure 4. PTB and NREL Data. PTB standard deviation $=0.04 \%$, NREL standard deviation $=0.03 \%$.

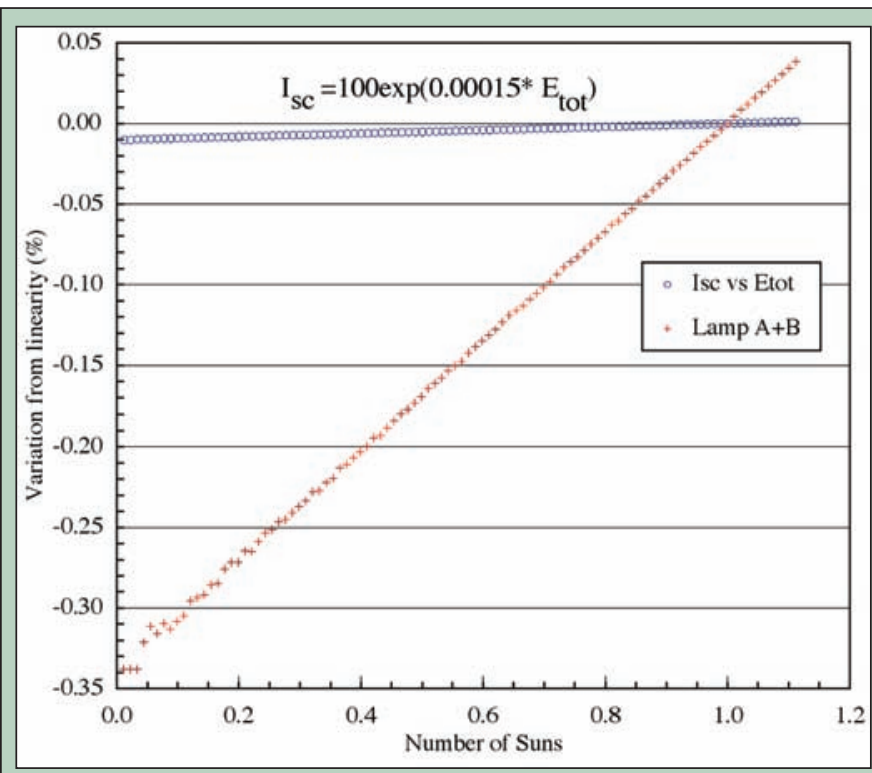

Figure 5. Exponential normalized numerical analysis. $\mathrm{E}_{\text {tot }}$ is transformed to number of suns.

Similarly doing the same study using the quadratic function in the form of $y=x A+B x$, where $A$ is $1.0055, B$ is 10 , and $y$ represents $\mathrm{I}_{\mathrm{sc}}$ and $\mathrm{x}$ represents $\mathrm{E}_{\text {tot }}$ further investigates the validity of the two lamp method. Using this function and graphing $\mathrm{I}_{\mathrm{sc}}$ versus $\mathrm{E}_{\text {tot }}$ gives the graphs seen in Figures 7-8. Similar to the exponential function, the graph of the quadratic function results in a $s$ value of $0.02 \%$ while the two lamp method results in a $s$ value of $0.0006 \%$. The two lamp method gives a value less than the actual $s$ value again due to the chosen range for $\mathrm{A}+\mathrm{B}$.

\section{DISCUSSION AND CONCLUSIONS}

The standards require that primary reference cells be linear over the total irradiance of interest [8]. Linearity is determined to be $2 \%$

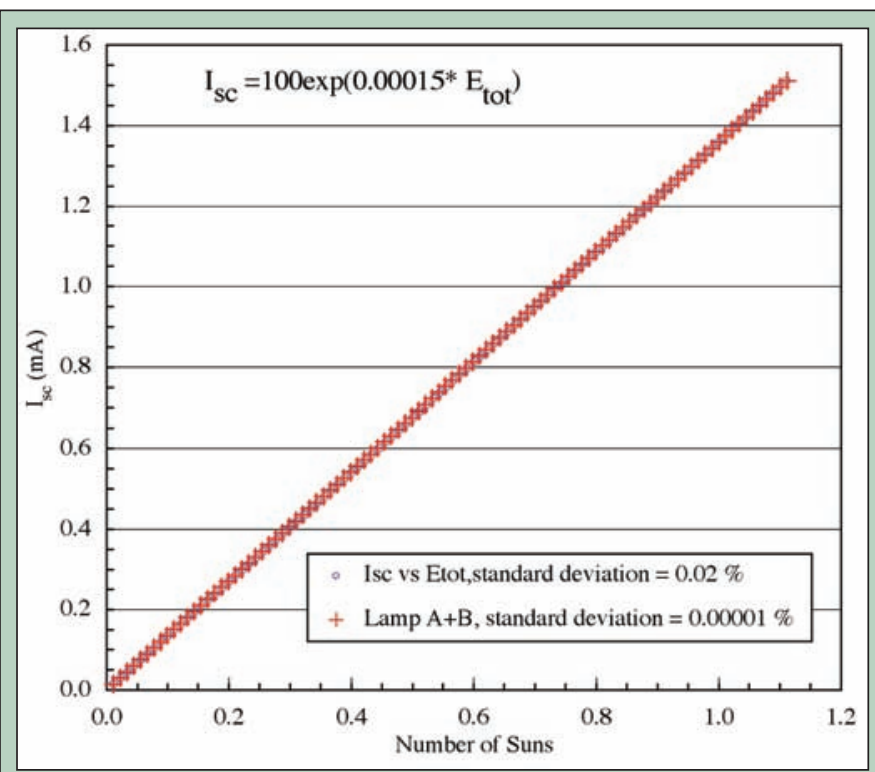

Figure 6. Exponential numerical analysis Isc vs $E_{\text {, standard deviation }}$ $=0.02 \%$. Lamp A + B standard deviation $=0.00001 \%$. $\mathrm{E}_{\text {tot }}$ is transformed to number of suns.

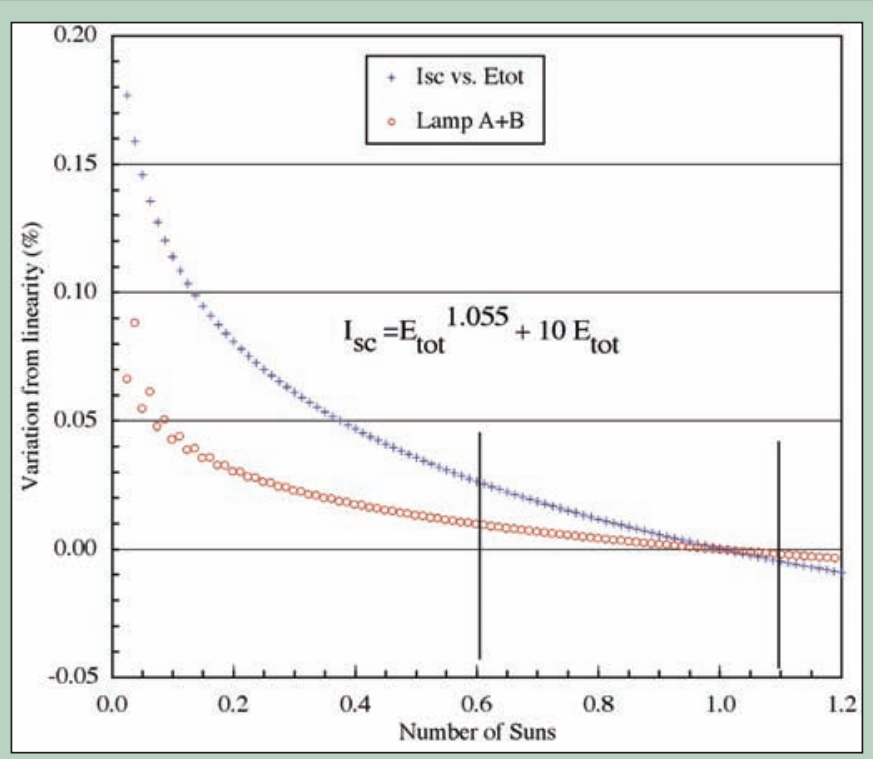

Figure 7. Quadratic normalized numerical analysis. $E_{\text {tot }}$ is transformed to number of suns.

standard deviation from the linear slope according to calibration standards [8]. The purpose of this test is to pass or fail primary reference cells as linear or nonlinear using the two lamp method. The 930216-1 sample calibrated by PTB is linear $[10,11]$ and the two lamp method also yields a linear response. This gives validity to the ability of the two lamp method to classify a reference cell as linear or nonlinear. What is found is that the two lamp method does not give the actual $s$ value of the response for the reference cell. A factor of at least 2 must be applied to the $s$ value given by the two lamp method in order to classify the cell as linear or nonlinear. Applying this factor in the Labview code is easily done so that the program will either pass or fail the cell immediately. A better approach may be 


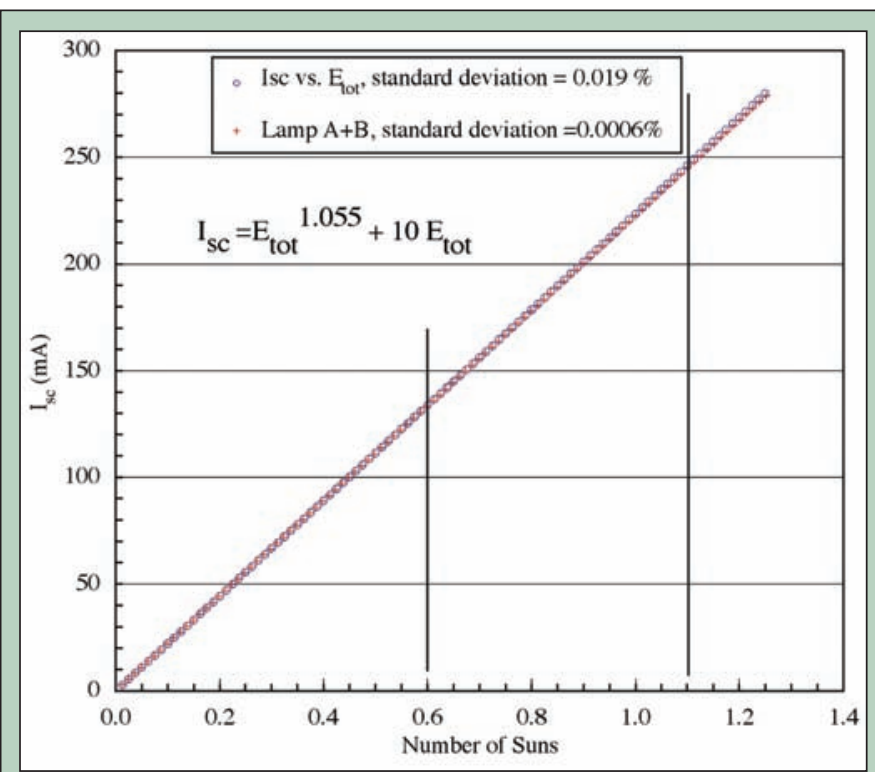

Figure 8. Exponential numerical analysis. I vs $E_{\text {, standard deviation }}$ $=0.019 \%$. Lamp A + B standard deviation $=0.006 \%$. $E_{\text {tot }}$ is transformed to number of suns.

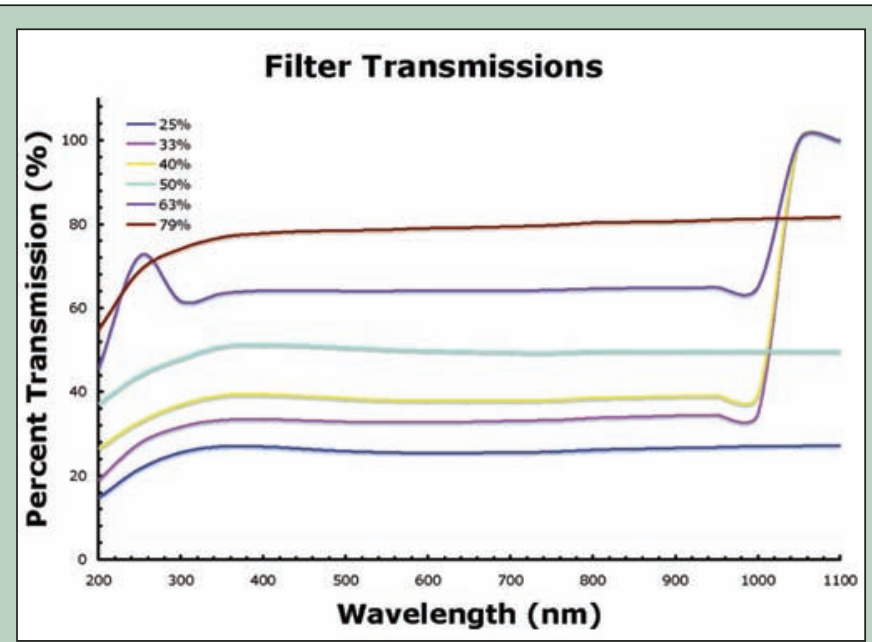

Figure 9. Percent transmission of filters in filter wheel. The opaque filter has a $0 \%$ transmission while the empty filter has $100 \%$ transmission (not shown on graph).

to set a window like the variation in nonlinearity over the intensity range of interest must be less than $2 \%$.

The overall response of a cell cannot be known before testing and by assuming nonlinearity overall, this test can be used at least as an initial check. The two lamp method places rather strict standards on a cell to be considered linear over the irradiance region of interest and correlates well with other linearity methods done around the world. This method gives a quick and easy way to classify linearity of the reference cell but this test will not however give the degree of nonlinearity if the cell is classified nonlinear.

\section{ACKNOWLEDGEMENTS}

The research was conducted at the NREL. We would like to thank the Department of Energy, Office of Science for the opportunity afforded to us in the PST and LSTPD programs. We would like to give special thanks to our mentor Keith Emery who guided us through this project. We would also like to thank the Franhofer Institute for Solar Energy Systems in Freidburg Germany for suggesting the concept. Thank you finally to the National Center for Photovoltaics and the NREL Office of Education Programs for their support. 


\section{REFERENCES}

[1] R. J. Chaffin and J.J. Wiczer, "Nonlinear response of GaAs Concentrator Cells to Solar Insulation," IEEE PVSC, vol. 15, no. 81, pp. 243-244, 1981.

[2] Joseph Burdick and Troy Glatfelter, "Spectral Response and I-V Measurements of Tandem Amorphous-Silicon Alloy Solar Cells," Solar Cells, vol. 18, pp. 301-314, 1986.

[3] R. W. Sanderson, J. D. Birkeland, S. C. Martin and C. E. Backus, "Performance of Silicon Solar Cells in the Concentration Range of 150 - 1500 Suns," IEEE PVSC, vol. 7, pp. 1309-1313, 1984.

[4] V. Augelli, L. Vasanelli, M. Leo, R. A. Leo, and G. Soliani, "Nonlinear Behavior of the Short Circuit Current of a Solar Cell with Minority Carrier Lifetime Dependent on the Light Intensity," Journal of Applied Physics, vol. 53, no. 3, pp. 1558-1562, 1982.

[5] J. Metzdorf, H. Kaase, "Nonlinearity and Spectral Mismatch Problems of Solar Cells," European Symposium Photovoltaic Generators in Space, vol. 4, no. 0, pp. 273277, 1984.

[6] J. Metzdorf, "Calibration of Solar Cells 1: The Differential Spectral Responsivity Method," Applied Optics, vol. 26, pp. 1701-1708, 1987.

[7] H. Mullegans, H. Bossong, E. D. Dunlop, "Temperature and Bias Light Dependence of Spectral Response Measurement," PV in Europe from PV Technology to Energy Solutions, pp. 7-10, 2002.

[8] American Society for Testing and Materials "Standard Test Method for Determining the Linearity of a Photovoltaic Device Parameter with Respect to a Test Parameter," ASTM Standard E1143, 1999

[9] National Institute for Standards and Technology (2004, July) Calibration Services [online] http://ts.nist.gov/ts/ htdocs/230/233/calibrations

[10] C.R. Osterwald, S. Anevsky, A.K. Barua, K. Bucher, P. Chauduri, J. Dubard, K. Emery, D. King, B. Hanses, J. Metzdorf, F. Nagamine, R. Shimokawa, Y.X. Wang, T. Wittchen, W. Zaaiman, A. Zastrow, and J. Zhang, "The Results of the PEP'93 Intercomparison of Reference Cell Calibrations and Newer Technology Performance Measurements: Final Report” pp. A3-3 - A3-4, 1998.

[11] Physikalisch-Technische Bundesanstalt "Calibration Certificate" PTB 930216-1, 2004.
[12] DFM Engineering, Inc. "DFM Engineering, Inc. filter Wheel System Description and Control Interface Manual Model FW-82" Longmont, CO, pp. 1-5.

[13] Spectra-Physics Lasers and Photonics "QTH/IR Lamp Housing Models 66860, 66861 Through 66884 Users Manual" Stratford, CT, pp. 1-17.

[14] Sorensen DC Products (2004, July) Power Supplies [online] http://www.elgar.com/products/Sorensen/index.htm

[15] Keith Emery, "Measurement and Characterization of Solar Cells and Modules," Handbook of Photovoltaic Science and Engineering, 1 ed., Ed. Antonio Luque and Steven Hegedus, West Sussex, England: John Wiley and Sons Ltd., 2003, pp. 701-752. 